\title{
Total Synthesis of (-)-Bolivianine
}

Synthesis of Natural

Products and

Potential Drugs

\section{Key words}

bolivianine

onoseriolide

intramolecular cyclopropanation

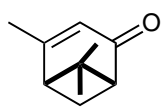

A

(+)-Verbenone

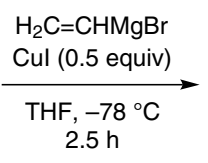

$86 \%$

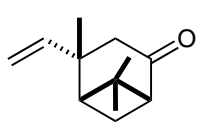

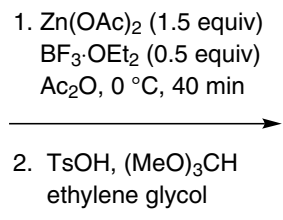

$73 \%$<smiles>C=C[C@]1(C)CC2(CC[C@H]1C(=C)C)OCCO2</smiles>

C
Diels-Alder

reaction

hetero-Diels-Alder reaction

domino reaction intram-catalyzed

cyclopropanation

1. $\mathrm{NaOMe}, \mathrm{MeOH}$

2. $\mathrm{Pd}_{2}(\mathrm{dba})_{3}$, THF $40{ }^{\circ} \mathrm{C}, 4 \mathrm{~h}$<smiles>C=C1C2CC2C2(C)Cc3occ(C(=O)OCC)c3CC12</smiles>

G

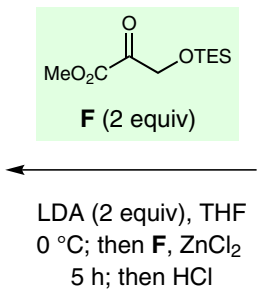

$43 \%$ (95\% brsm)

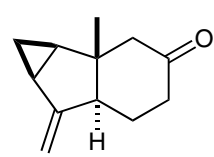

E

\section{3. $\mathrm{TsOH}$ ( 0.5 equiv) acetone- $\mathrm{H}_{2} \mathrm{O}$}

$59 \%$
Significance: The first total synthesis of (-)-bolivianine, a sesquiterpenoid isolated from the trunk bark of the Andean forest tree Hedyosmum angustifolium, is reported together with some interesting preliminary experiments on possible biosynthetic pathways. The synthetic route devised towards this natural product which harbors nine contiguous stereogenic centers within a complex heptacyclic scaffold thereby affords the target molecule in only 15 steps from commercially available (+)-verbenone.

SYNFACTS Contributors: Erick M. Carreira, Nikolas Huwyler Synfacts 2013, 9(9), 0915 Published online: 19.08.2013 Dol: 10.1055/s-0033-1339553; Reg-No.: C04513SF
Comment: The synthetic strategy is based on the insight that (-)-bolivianine could be biosynthetically derived from onoseriolide and $(E)$-ocimene (I), both of which are constituents of Hedyosmum angustifolium as well. While onoseriolide itself did not react with diene I even at elevated temperatures, the oxidized derivative $\mathbf{H}$ was found to undergo the desired Diels-Alder/hetero-Diels-Alder domino reaction to afford the targeted natural product as a single regio- and diastereoisomer. Another salient feature of the synthesis is the palladium-catalyzed intramolecular cyclopropanation. 